\title{
ANALISIS KELAYAKAN USAHA KRIPIK RUMPUT LAUT UDANG EBI (STUDI KASUS DI UD. ORA ET LABORA KOTA MATARAM)
}

\author{
I DEWA GEDE SUARTHA ${ }^{1)}$, MADE SUMA WEDASTRA ${ }^{2)}$, SILFIA HERLINA ${ }^{3)}$ \\ Fakultas Pertanian UNMAS Mataram \\ ${ }^{1)}$ dsuartha@ymail.com ${ }^{2)}$ madesumawedastra17@gmail.com, ${ }^{3)}$ silfiaherlina120789@gmail.com
}

\begin{abstract}
ABSTRAK
Secara bisnis setiap korbanan yang dikeluarkan bertujuan untuk mendapatkan manfaat (benefit). Begitu pula pada usaha kripik rumput laut udang ebi di UD. Ora Et Labora Kota Mataram. Agar sumber daya yang digunakan bermanfaat, maka usaha kripik rumput laut udang ebi perlu dianalisis kelayakannya. Sementara informasi kelayakan usaha kripik rumput laut udang ebi pada UD. Ora Et Labora Kota Mataram belum tersedia, sehingga dukungan dari penelitian sangat dibutuhkan. Pemilihan UD. Ora Et labora Kota Mataram sebagai lokasi penelitian dilakukan secara purposive sampling dengan jumlah sampel tiga orang yang juga dilakukan secara purposive sampling.

Hasil penelitian menunjukkan, bahwa usaha kripik rumput laut udang ebi layak dilaksanakan oleh UD. Ora Et labora Kota Mataram dengan ROI $=35,33 \% ; \mathrm{B} / \mathrm{C}=1,11$ dan $\mathrm{BEP}=181,78$ bungkus.
\end{abstract}

Kata kunci : Kelayakan usaha, kripik rumput laut udang ebi.

\begin{abstract}
In business, every expenditure issued aims to get benefits. Similarly, in the business of ebi shrimp seaweed chips at UD. Ora Et Labora Kota Mataram. In order for the resources used to be useful, the ebi shrimp seaweed chip business needs to be analyzed for its feasibility. While information on the business feasibility of ebi shrimp seaweed chips at UD. Ora Et Labora Kota Mataram is not yet available, so support from research is needed. Selection of UD. Ora Et labora of Mataram City as the location of the study was conducted by purposive sampling with a sample of three people which was also done by purposive sampling.

The results showed that the ebi shrimp seaweed chips business was feasible to be carried out by UD. Ora Et labora Kota Mataram with ROI = 35.33\%; B / C = 1.11 and BEP = 181.78 packs.
\end{abstract}

Keywords: Business feasibility, ebi shrimp seaweed chips.

\section{PENDAHULUAN}

\section{Latar Belakang}

Rumput laut merupakan sumber utama penghasil agar-agar, alginate dan karagin yang banyak dimanfaatkan dalam industri makanan, kosmetik, farmasi dan industri lainnya seperti industri kertas, tekstil, potografi, pasta dan pengalengan ikan. Produksi produksi rumput laut Tahun 2009 mencapai 2,7 juta ton, pada Tahun 2010 meningkat 3,1 juta ton, selanjutnya Tahun 2011 naik menjadi 4,3 juta ton. Hal ini menjadi alasan mengapa rumput laut merupakan salah satu produk unggulan dalam kebijakan pemerintah yang akan menjadikan Indonesia sebagai penghasil produk perikanan laut terbesar di dunia pada tahun 2015 (Pandelaki, 2012).

Kementerian Kelautan dan Perikanan (KKP) bekerjasama dengan SEAMEO BIOTROP Bogor telah melakukan kerjasama untuk meningkatkan kualitas bibit rumput laut Eucheumacottonii atau sering disebut Kappaphycus alvarezii melalui teknik kultul jaringan pada tahun 2011. Pengembangan rumput laut terus dilakukan oleh Balai Besar Pengembangan Budidaya di laut Lampung untuk menyediakan bibit bagi pembudidayaan. Upaya pengembangan bibit rumput laut berhasil dilakukan dan telah didistribusikan ke beberapa wilayah Teluk Lampung, salah satunya kecamatan Ketapang Lampung Selatan (Runtuboy, 2014).

Nuryanto dkk. (2016) mengatakan rumput laut pantas menjadi komoditas utama dalam program revitalisasi kelautan dan perikanan di samping udang dan tuna karena beberapa keunggulannya antara lain: peluang ekspor terbuka luas, harga relatif stabil, belum ada quota perdagangan bagi rumput laut, teknologi pembudidayaannya sederhana, mudah dikuasai, siklus pembudidayaannya relatif singkat, sehingga cepat memberikan keuntungan dan kebutuhan modal relatif kecil. Rumput laut merupakan komoditas yang 
tak tergantikan karena tidak ada produk sintetisnya, usaha pembudidayaan rumput laut tergolong usaha yang padat karya, sehingga mampu menyerap tenaga kerja.

Rumput laut merupakan salah satu hasil perikanan yang cukup penting sebagai sumber penghasil devisa negara yang telah banyak dimanfaatkan secara tradisional sebagai bahan makanan dan obat-obatan. Dewasa ini pemanfaatan rumput laut semakin berkembang dan sudah mencapai skala industri antara lain dalam industri pangan, kosmetik, makanan, fannasi dan berbagai industri lainnya. Euchema coftonii merupakan salah satu jenis rumput laut yang banyak digunakan karena mengandung karagenan, agar dan alginate (Sembiring, Sri Ismiati, 2002)

UD. Ora Et Labora Kota Mataram merupakan salah satu usaha dagang yang memproduksi berbagai jenis makanan dengan bahan baku rumput laut, seperti kripik rumput laut daun jarak, kripik rumput laut ubi unggu, kripik rumput laut kangkung, kripik rumput laut udang ebi, aneka stick, stick buah naga kangkung. Dari jenis produk dengan bahan baku rumput yang diproduksi UD. Ora Et labora, yang menarik untuk diteliti adalah kripik rumput laut udang ebi karena kripik ini lebih banyak diminati konsumen.

Kripik rumput laut udang ebi adalah kripik dengan bahan baku rumput laut yang dicampur dengan tepung terigu, tepung kanji, bawang putih, gula, beaking powder, cabe keriting, sasa, garam, air dan udang ebi yang digoreng. Merubah rumput laut menjadi kripik rumput laut udang ebi, tentunya membutuhkan sumber daya berupa modal kerja yang perlu diperhitungkan kelayakannya.

Hapsari Tria Kusumawardani, dkk., (2017), menyatakan umumnya perusahaan didirikan dengan tujuan utama mendapatkan keuntungan atau laba. Perolehan laba atau keuntungan akan menjadi tolak ukur bagi manajemen perusahaan sebagai pandangan untuk melihat kesempatan maupun peluang dimasa yang akan datang. Laba atau keuntungan diperoleh dari hasil operasi perusahaan dalam periode tertentu guna meningkatkan efisiensi dan efektifitas perusahaan.

Murti Sumarni, dkk. (1998) menyatakan bahwa dalam perusahaan sumber-sumber ekonomi diproses agar menjadi barang/jasa yang akan ditujukan untuk memuaskan kebutuhan konsumen sekaligus dapat memberikan keuntungan bagi perusahaan. Untuk mencapai tujuan tersebut, diterapkan prinsip ekonomi yaitu dengan pengorbanan tertentu diharapkan dapat diperoleh hasil atau keuntungan maksimum.

Kedua pendapat ahli di atas dapat disimpulkan, bahwa setiap perusahaan, termasuk UD. Ora Et Labora Kota Mataram berkepentingan mengetahui informasi kelayakan usaha yang dijalankan, sehingga dapat diketahui dengan pasti sejauh mana dana yang dinvestasikan pada usaha kripik rumput laut udang ebi memberikan manfaat (benefit). Sementara informasi tentang layak tidaknya usaha yang dijalankan UD. Ora Et labora Kota Mataram, khususnya usaha kripik rumput laut udang ebi belum tersedia. Ketidaktersediaan informasi ini disebabkan, karena SDM yang dimiliki kurang memadai baik kuantitas maupun kualitas. Dengan demikian diperlukan dukungan hasil penelitian tentang analisis kelayakan usaha kripik rumput laut udang ebi.

\section{Rumusan Masalah}

Berdasarkan uraian di atas dapat dirumuskan permasalahan apakah usaha kripik rumput laut udang ebi di UD. Ora Et Labora Kota Mataram sudah dikatakan layak secara financial ?

\section{Tujuan dan Manfaat Penelitian}

Penelitian ini bertujuan : untuk mengetahui kelayakan usaha kripik rumput laut udang ebi di UD. Ora Et Labora Kota Mataram secara financial dengan metode tanpa diskonto.

Hasil penelitian ini diharapkan dapat digunakan sebagai bahan pertimbangan bagi :

a. Pengusaha pemula yang ingin berinvestasi di bidang usaha kripik rumput laut udang ebi.

b. UD. Ora Et Labora dalam mengembangkan usaha kripik rumput laut udang ebi ke arah yang lebih maju.

\section{METODE PENELITIAN}

\section{Tempat Penelitian.}

Penelitian ini dilaksanakan di UD. Ora Et labora Kota Mataram, secara purposive sampling, yakni pemilihan lokasi penelitian secara sengaja atas dasar, bahwa UD. Ora Et labora Kota Mataram merupakan UD yang memproduksi kripik rumput laut udang ebi, serta sudah memasarkan produknya di seluruh wilayah Mataram. 


\section{Penentuan Responden}

Penentuan responden penelitian ditentukan secara purposive sampling, yaitu memilih 1 orang pemilik usaha, 1 orang bagian produksi dan 1 orang bagian pemasaran. Alasan penentuan responden ini, karena yang bersangkutan mengetahui bidang-bidang tugasnya masing-masing.

\section{Ruang Lingkup Penelitian.}

Penelitian ini dibatasi pada ruang lingkup analisis kelayakan usaha kripik rumput laut udang ebi dari sisi financial dengan metode tanpa diskonto. Dengan demikian data yang akan dianalisis adalah data tahun 2018.

\section{Metode Pengumpulan Data}

Metode pengumpulan data yang digunakan dalam penelitian ini antara lain : Observasi lapangan, wawancara dan Dokumentasi

\section{Metode Analisis Data}

Data kuantitatif yang terkumpul dianalisis dengan menggunakan analisis kelayakan usaha metode non diskonto yang meliputi :

1.Return On Invesment (ROI) dengan rumus :

$$
\mathrm{ROI}=\frac{E A T}{\text { Total Aktiva }}
$$

Keterangan : Earning After Tax $($ EAT $)=$ Pendapatan bersih setelah pajak, Total Aktiva $=$ Aktiva Lancar + Aktiva Tetap

\section{Benefit Cost Ratio (B/C Ratio)}

$\mathrm{B} / \mathrm{C}=\frac{P W \text { Benefit }}{P W \text { Cost }}($ Gittinger, 1986; dalam Tia Aprilia Zakita, 2018)

Keterangan : PW Benefit $=$ Present Worth Benefit $($ Kemanfaatan yang dinilai dengan harga sekarang/pasar $)$ $P W$ Cost $=$ Present Worth Cost (Biaya yang dinilai dengan harga sekarang)

Keputusan :

Jika $\mathrm{B} / \mathrm{C}$ ratio > 1 , usaha layak dilaksanakan

Jika $\mathrm{B} / \mathrm{C}$ ratio $<1$, usaha tidak layak atau merugi

\section{Break Even Point (BEP)}

$\mathrm{BEP}=\frac{F C}{P-V C}($ Bambang Riyanto, 2011; dalam Tia Aprilia Zakita, 2018)

Keterangan :

Fixed Cost $(\mathrm{FC})=$ Biaya tetap yang nilainya cenderung stabil tanpa dipengaruhi unit yang diproduksi

Price $(\mathrm{P})=$ Harga jual per unit

Variabel Cost $(\mathrm{V})$ = Biaya variabel yang besar nilainya tergantung pada banyak sedikitnya jumlah barang yang diproduksi.

\section{HASIL DAN PEMBAHASAN}

\section{Analisis Kelayakan Usaha Kripik Rumput Laut Udang Ebi UD. Ora Et Labora Kota Mataram}

Bagi perusahaan, laporan keuangan akan disusun menurut prinsip-prinsip akuntansi dan karenanya para pemakai laporan keuangan perlu memahami cara penyajian informasi keuangan tersebut. Ada dua laporan keuangan perusahaan yang pokok, yaitu Neraca dan Laporan Rugi-laba. Neraca menunjukkan posisi kekayaan, kewajiban keuangan dan modal sendiri perusahaan pada waktu tertentu. Kekayaan disajikan pada sisi aktiva, sedangkan kewajiban dan modal sendiri pada sisi pasiva. Sedangkan laporan Rugi-Laba menunjukkan laba atau rugi yang diperoleh perusahaan dalam periode waktu tertentu (misalnya 1 tahun).

Kaitannya dengan laporan keuangan, UD. Ora Et Labora Kota Mataram selama tahun 2018 berturutturut disajikan antara lain : 
Tabel 1. Neraca UD. Ora Et Labora Kota Mataram pada 31 Desember 2018

\begin{tabular}{|c|c|c|}
\hline $\begin{array}{l}\text { Aktiva } \\
\text { Aktiva Lancar } \\
-\quad \text { Kas } \\
-\quad \text { Piutang dagang }\end{array}$ & $\begin{array}{l}\text { Pasiva } \\
\text { Hutang lancar } \\
-\quad \text { Hutang dagang }\end{array}$ & Rp. 2.000 .000 \\
\hline $\begin{array}{lr}\text { Total aktiva lancar } & \text { Rp.13.000.000 } \\
\text { Aktiva Tetap } & \text { Rp. } 2.362 .000 \text {. } \\
-\quad \text { Akumulasi penyusutan Rp. }(105.240) \\
\text { Total Aktiva Tetap } & \text { Rp. } 2.256 .760 \\
\end{array}$ & $\begin{array}{l}\text { Total hutang lancar } \\
\text { Modal }\end{array}$ & $\begin{array}{l}\text { Rp. } 2.000 .000 \\
\text { Rp.13.256.760 }\end{array}$ \\
\hline Total Aktiva $\quad$ Rp. 15.256 .760 & Total Pasiva & Rp. 15.256 .760 \\
\hline
\end{tabular}

Sumber : UD. Ora Et Labora

Dari Tabel 1di atas dapat dijelaskan, bahwa total aktiva lancar lebih besar dibvandingkan total hutang lancer. Kondisi keuangan seperti ini menunjukkan, bahwa UD. Ora Et Labora Kota Mataram dalam kondisi sehat.

Tabel. 2. Rugi-Laba UD. Ora Et Labora Kota Mataram 31 Desember 2018

\begin{tabular}{|c|l|r|}
\hline No. & \multicolumn{1}{|c|}{ Uraian } & Besar (Rp.) \\
\hline 1 & Nilai penjualan & 13.650 .000 \\
\hline 2 & Harga pokok penjualan & 6.282 .240 \\
\hline 3 & Laba kotor & 7.367 .760 \\
\hline 4 & Biaya umum dan administrasi penjualan & 180.000 \\
\hline 5 & Laba sebelum bunga dan pajak (EBIT) & 7.187 .760 \\
\hline 6 & Bunga pinjaman jangka panjang & 0 \\
\hline 7 & Laba sebelum pajak & 7.187 .760 \\
\hline 8 & Pajak 25\% & 1.796 .940 \\
\hline 9 & Laba bersih (EAT) & 5.390 .820 \\
\hline
\end{tabular}

Sumber : Data primer diolah

Dari Tabel 2. di atas dapat dijelaskan, bahwa nilai penjualan selama tiga kali proses produksi dalam setahun adalah sebesar 20.920.000 rupiah dengan harga pokok penjualan 6.282.240 rupiah. Dengan demikian laba kotor yang dihasilkan sebesar 4.637.760 rupiah. Selanjutnya laba sebelum bunga dan pajak (EBIT) sebesar 4.457.760 rupiah dan laba bersih (EAT) sebesar 3.343.320 rupiah.

Dari data pada Tabel 1 dan 2 dapat dihitung besarnya kreteria kelayakan usaha kripik rumput laut udang ebi sebagai berikut :

1. $\quad$ ROI $=\frac{E A T}{\text { Total Aktiva }}=\frac{5.390 .820}{15.256 .760}=35,33 \%$. Angka ini bila ditinjau dari sisi kelayakan usaha, maka usaha kripik rumput laut udang ebi yang diproduksi oleh UD. Ora Et Labora Kota Mataram tergolong layak, karena menghasilkan pendapatan bersih sebesar 35,33\% dari total aktiva yang dimiliki.

2. $\mathbf{B} / \mathbf{C}=\frac{P W \text { Benefit }}{P W \text { Cost }}=\frac{7.187 .760}{6.462 .240}=1,11$. Angka ini bila dilihat dari kelayakan usaha, maka usaha kripik rumput laut udang ebi yang diproduksi oleh UD. Ora Et Labora Kota Mataram tergolong layak, karena pendapatan bersih lebih besar dari biaya yang dikorbankan.

3. $\mathbf{B E P}=\frac{F C}{P-V C}=\frac{2.362 .000}{13.000-6.15}=\frac{2.362 .000}{12.993,5}=181,78$ unit. Angka ini menunjukkan, bahwa untuk mempertahankan kelayakan usaha kripik rumput laut udang ebi yang diproduksi oleh UD. Ora Et Labora Kota Mataram tergolong layak, maka harus memproduksi kripik rumput laut udang ebi paling sedikit 181,78 bungkus. Jumlah ini masih jauh lebih sedikit dibandingkan kemampuan memproduksi dalam waktu setahun sebanyak 1.050 .000 bungkus. 


\section{SIMPULAN DAN SARAN}

\section{Simpulan}

Dari hasil penelitian di atas dapat disimpulkan, bahwa usaha kripik rumput laut udang ebi yang dijalankan oleh UD. Ora Et Labora Kota Mataram tergolong layak dengan ROI $=35,33 \% ; \mathrm{B} / \mathrm{C}=1,11$ dan $\mathrm{BEP}=181,78$ bungkus, dimana nilai $\mathrm{BEP}=181,78$ jauh lebih sedikit dari kemampuan memproduksi dalam waktu setahun sebanyak 1.050 bungkus.

\section{Saran-saran}

Oleh karena usaha kripik rumput laut udang ebi layak dilaksanakan, maka disarankan agar UD. Ora Et Labora Kota Mataram meningkatkan volume produksinya dibarengi dengan perluasan pasar.

\section{DAFTAR PUSTAKA}

Ardia Desti Rahayu, 2015. Analisis Kelayakan Gula Semut Anggota Koperasi Serba Usaha (KSP), Skripsi Fakultas Ekonomi Universitas Negeri Yogyakarta

Hapsari Tria Kusuma Wardani, M. Dzulkirom AR, 2017. Analisis Break Even Point Sebagai Dasar Kebijakan Perencanaan Penjualan Dan Laba (Studi Pada PT. Industri Marmer Indonesia Tulungagung Periode 2014-2016, Jurnal Administrasi Bisnis.

Muljadi Pudjosumarto, 1985. Evaluasi Proyek Uraian Singkat Dan Tanya Jawab, Libertty Yogyakarta.

Nuryanto, Lutfi Aris Sasongko dan Eka Dewi Nurjayanti, 2016. Analisis Kelayakan Usaha Rumput Laut (Eucheuma Cottonii) (Studi Kasus Desa Karimun Jawa, Kecamatan Karimun Kabupaten Jepara, Mediagro

Pandelaki, 2012. Strategi Pengembangan Rumput laut di Pulau Nain Kabupaten Minahasa Utara, Jurnal Perikanan dan Kelautan.

Runtuboy, N. 2014. Transfortasi Bibit Rumput laut di Bali Besar Pengembangan Budidaya Laut (BBPBL) Lampung, Divisi Budidaya Rumput laut BBPBL Lampung.

Sembiring, Sri Ismiati, 2002. Pemanfaatan Rumput Laut Euchema Cottonii Sebagai bahan Baku Pembuatan Permen Jelly, http://repository.ipb/handle/123456789/19122

Suad Husnan dan Suwarsono Muhamad, 2000. Studi Kelayakan Bisnis Proyek, UPP AMP YKPN

Tia Aprilia Zakita, 2018. Analisis Kelayakan Usaha Pada Industri Tempe di Desa Purwodadi Dalam Kecamatan Tanjung Sari Kabupaten Lampung Selatan, Fakultas Ekonomi Universitas Lampung. 